\title{
Associations between breastfeeding and cognitive function in children from early childhood to school age: a prospective birth cohort study
}

\author{
Kyoung Min Kim ${ }^{1,2^{*}}$ (D) and Jae-Won $\mathrm{Choi}^{3^{*}}$ (D)
}

\begin{abstract}
Background: Despite evidences of breastfeeding for preventing acute physical illnesses in infants, the evidence for the association between breastfeeding and long-term cognitive development is not yet convincing.

Methods: The data of nationwide representative sample of 1752 children born between 2008 and 2009 in Korea were prospectively assessed from the fetal period to examine the benefits of breastfeeding and cognitive development. Breastfeeding duration was prospectively assessed by parents. The Korean Ages and Stages Questionnaire and the Korean version of Denver II were used to assess early development annually from 5.5 to 26.2 months of age. Language development at 3 years of age was assessed with Receptive and Expressive Vocabulary Tests. Cognitive function at 8 years of age was assessed using multifactorial intelligence test.

Results: In the analysis of categorical variables, children who were breastfed for $>1$ and $\leq 3$ months displayed significantly higher odds ratios for delayed development assessed with Korean Ages and Stages Questionnaire at 14.1 months than those breastfed for $>3$ and $\leq 6$ months $(\mathrm{OR}=2.21 ; 95 \% \mathrm{Cl}: 1.08,4.50)$, but no significant differences in other rounds of assessments. In the analysis with continuous variables, there were significant differences among six groups of breastfeeding duration in communication ( $F=3.72 ; p<0.002)$ and problem solving $(F=3.09 ; p<0.009)$ at 14.1 months, expressive language $(F=3.74 ; p=0.002)$ at 3 years, and calculation $(F=2.43 ; p<$ $0.033)$ at 8 years. When analyzed by two groups, children breastfed for $>3$ months scored significantly higher on the communication ( $F=17.71 ; p<0.001)$ and problem-solving $(F=11.26 ; p<0.001)$ subscales at 14.1 months, and expressive language $(F=12.85 ; p<0.001)$ at 3 years, and vocabulary $(F=6.78 ; p=0.009)$ and language inference $(F=5.62 ; p=0.018)$ at 8 years, compared to children breastfed for 3 months or less.

Conclusion: We found that cognitive development was improved in children that were breastfed for $>3$ months. Although these results are supported by previous studies, it is important to note that other factors were reported as larger determinants of cognitive development than breastfeeding. Future studies that examine the underlying mechanism for the association between breastfeeding and cognitive development are warranted.
\end{abstract}

Keywords: Breastfeeding, Cognitive development, Childhood, School-age children

\footnotetext{
* Correspondence: profuture@naver.com; lingker77@naver.com

'Department of Psychiatry, Dankook University Hospital, Cheonan, Republic

of Korea

${ }^{3}$ Department of Psychiatry, Gyeongsang National University Hospital, 79,

Gangnam-ro, Jinju-si, Gyeongsangnam-do 52727, Republic of Korea

Full list of author information is available at the end of the article
}

C The Author(s). 2020 Open Access This article is licensed under a Creative Commons Attribution 4.0 International License, which permits use, sharing, adaptation, distribution and reproduction in any medium or format, as long as you give appropriate credit to the original author(s) and the source, provide a link to the Creative Commons licence, and indicate if changes were made. The images or other third party material in this article are included in the article's Creative Commons licence, unless indicated otherwise in a credit line to the material. If material is not included in the article's Creative Commons licence and your intended use is not permitted by statutory regulation or exceeds the permitted use, you will need to obtain permission directly from the copyright holder. To view a copy of this licence, visit http://creativecommons.org/licenses/by/4.0/. The Creative Commons Public Domain Dedication waiver (http://creativecommons.org/publicdomain/zero/1.0/) applies to the data made available in this article, unless otherwise stated in a credit line to the data. 


\section{Background}

Breastfeeding is an important component of nutrition for infants and it provides various health benefits to the child and mother [1]. Breastfeeding has clear short-term benefits for reducing morbidity and mortality from infectious disease in infants [2]. Breastfeeding provides health benefits and prevention of acute physical illnesses including gastrointestinal illnesses, otitis media, respiratory tract infections, and neonatal necrotizing enterocolitis to infants $[1,3]$. Breastfeeding may also prevent infants from developing chronic diseases such as asthma, allergies, and obesity [1].

Cognitive development in children has been another effect examined in breastfeeding research. The topic was first studied by Hoefer and Hardy in 1929 and multiple other studies have since examined the associations between breastfeeding and cognitive function of children with consistently reported positive associations [4]. A meta-analysis of 11 studies reported that infants who were breastfed had higher intelligence quotients (IQ) by 5.32 points (unadjusted) and 3.16 points when adjusted for covariates [5]. In addition, the higher levels of cognitive function observed in breastfed infants were stable across successive ages. A more recent meta-analysis of 17 studies on the relationship between breastfeeding and intelligence reported that breastfed subjects presented a higher IQ by 3.44 points or by 2.62 points when controlled for maternal IQ [6].

A randomized experiment performed with consideration of the concerns raised regarding previous observational studies also reported significantly higher verbal IQ, performance IQ, and full-scale IQ in the breastfed group by 7.5, 2.9 and 5.9 points, respectively [7]. The breastfed group also scored higher in teacher ratings of both reading and writing. Likewise, cross-population studies of British and Brazilian cohorts reported that longer breastfeeding duration was related to higher IQ scores by 3-6 points [8]. The cognitive benefits of breastfeeding were reported to persist into adulthood. IQ scores at the age of 30 were 3.76 points higher in participants who were breastfed for $\geq 12$ months compared to those who were breastfed for $<1$ month [9].

Despite the evidence for the positive associations between breastfeeding and cognitive development by multiple studies within various populations, there are few studies that have employed multiple assessment tools and repetitive assessment of cognitive development at multiple points. In addition, previous studies in the Korean population, especially using prospective methods, are sparse. A study of the Korean population reported significantly higher IQ by 4.07 points in breastfed children compared to non-breastfed children assessed at age of 9 years [10]. Kim et al. reported that breastfed Korean children had significantly higher learning quotient scores in speaking, reading, writing, spelling, and mathematical calculation than children who were never-breastfed [11]. However, these studies were based on a cross-sectional sample and retrospective information on breastfeeding; therefore, the causal relationship between breastfeeding and learning skills cannot be drawn and recall bias is possible in these studies. The present study aims to examine the associations between breastfeeding and cognitive development in Korean children from ages of 1-8 years using multimodal and multi-informant assessment and a prospective study design.

\section{Methods}

\section{Participants}

The present study utilized data collected from the Panel Study on Korean Children (PSKC). The PSKC is an ongoing longitudinal panel study conducted by the Korea Institute of Child Care and Education since 2008. The participants in PSKC were invited by stratified multistage sampling using resident registration data to represent all nationwide household populations. A total of 2150 children born between 2008 and 2009 in Korea were enrolled in the study from the fetal period and evaluated prospectively for breastfeeding and cognitive development at 5.5 (T1), 14.1 (T2), 26.2 (T3), 38.7 (T4), and 99.2 (T9) months of age. Because of the challenges of longitudinal cohort studies, there was some missing data for the follow-up assessments. In our study, we analyzed data collected from 1752 children whose assessments of breastfeeding and K-ASQ at T3 (26.2 months) were present.

\section{Measurements}

Demographic variables including the child's sex, age, gestational period, birth weight, parents' education level, and household income were assessed by paper and pencil interviews and computer-assisted personal interviews. Breastfeeding data from T1 (5.5 months) to T4 (38.7 months) was prospectively collected by computerassisted personal interviews.

\section{Early development}

To assess early cognitive development at T1 (5.5 months), T2 (14.1 months), and T3 (26.2 months), the participants were assessed using the Korean Ages and Stages Questionnaires (K-ASQ) and the Korean version of Denver II, which are widely used screening tools for early development. K-ASQ is a screening tool for the developmental progress of infants and toddlers as rated by parents [12]. The K-ASQ comprised 30 items rated on three-point Likert scales under the following five subdomains: communication, gross motor, fine motor, problem-solving, and personal-social [13]. Scores that were two standard deviations below the average in each 
subdomain were coded as atypical. Denver II is another screening tool for early development with a validated Korean version [14, 15]. Denver II codes the development of children to the dichotomous outcomes of "normal" or "suspicious" based on the assessment scores. Denver II comprised four subdomains: personal-social, fine motor/adaptive, language, and gross motor. K-ASQ and Denver II could not be included because of copyright; however, additional information regarding both tools can be obtained from the Panel Study on Korean Children website [16].

\section{Cognitive function in middle childhood and school age}

Language abilities at T4 (38.7 months) were assessed by the Receptive and Expressive Vocabulary Test (REVT), which is comprised of 185 Korean vocabulary items and two subscales of receptive and expressive language tests [17]. The REVT results were coded to the percentile scores of $1(<10 \%)$ to $11(100 \%)$ as a continuous variable and "Normal or mildly delayed" and "Markedly delayed" as binary categorical variables. The cognitive function of school-age children at T9 (99.2 months) was assessed in terms of intelligence and academic performance. The intelligence of children was assessed using the multifactorial intelligence test (M-FIT). The M-FIT is comprised of six subdomains (vocabulary, language inference, schematization, calculation, spatial perception, and reasoning), each with 20 item tests. The scores of M-FIT are presented with the T-score and percentile score $(0-$ 100) based on normative data. Our analysis used the Tscore, which is a norm-referenced standardized score with a mean of 50 points and standard deviation of 10 points. The T-score of $\leq 37$ on each subscale was labeled as "delayed," and the participants with the "delayed" scores on at least one subscale were categorized as "delayed" for the categorical analysis.

\section{Statistical analysis}

Although the criterion for breastfeeding duration to group participants vary widely in previous studies, many studies included "never," "1 month," "3 months," "6 months," and "12 months" as the duration criteria [6]. In our study, participants were grouped by the following breastfeeding durations according to previous studies $[9,18]$ : "never," "up to 1 month," "1-3 months," "3-6 months," "6-12 months, " "12-18 months" and "over 18 months." We used logistic regression to investigate the odds ratio for delayed development of the early period (T1, 5.5 months to T3, 26.2 months) assessed by Denver II and K-ASQ. To compare the outcomes of K-ASQ as continuous variables, language ability at T4 (38.7 months), and intelligence and academic function at T9 (99.2 months) among the groups of breastfeeding duration, analysis of variance (ANOVA) and analysis of covariance (ANCOVA) were utilized. In all analyses, the adjusted model included the children's sex, age, gestational age, birth weight, parents' education level, and household income as covariates. To adjust for multiple comparisons included in our analysis, we performed the Benjamini-Hochberg test with a false discovery rate threshold of 0.05 for the crude and adjusted models, respectively [19]. Statistical analyses were conducted using the software package SPSS 25.0 for Windows (IBM Co., Armonk, NY, USA).

\section{Ethics}

We provided parents with information on the purpose and procedure of the study and written informed consent was obtained from parents before enrollment. This study was performed in accordance with the ethical standards laid down in the 1964 Declaration of Helsinki and its later amendments. The study protocol was approved by the Institutional Review Board of the Korean Institute of Child Care of Education (KICCEIRB-2016-07).

\section{Results \\ Demographic characteristics and prevalence of breastfeeding}

Among the 2150 children enrolled in the study, 1752 children, whose assessment findings for breastfeeding and KASQ at the age of 14 months were available, were included in the final analysis. Among them, 1632, 1704, 1752, 1630, and 1398 children were included in the analysis of each assessment wave at 5.5 (T1), 14.1 (T2), 26,2 (T3), 38.7 (T4), and 99.2 (T9) months of age, respectively, because of some missing assessments and dropouts at follow-up.

The demographic characteristics of participants are presented in Table 1 and the geographical distribution of participants is presented in Table S1. Of the total participants, $893(51 \%)$ children were male, 52 (3.0\%) children were born preterm and 49 (2.8\%) children were born with low birth weights. The mean T1 household income of participants included in the analysis was 3193 (SD = 1462) thousand KRW. It is similar to the Korean national household income level (mean $=3390$ thousand KRW) in 2008 [20] and is not significantly different from the income of the excluded participants (mean $=3299 ; \mathrm{SD}=$ 1653 thousand KRW; $\mathrm{F}=1.35 ; p=0.245$ ). Moreover, the regional distribution of included participants was not significantly different from the excluded participants (Table S1). These findings indicate that our sample was not susceptible to the selection and attrition bias.

The prevalence and duration of breastfeeding are presented in Table 2. The proportion of children who were ever-breastfed in our study was $97.4 \%$. The proportion of never-breastfed children was $2.6 \%$ and children who were breastfed for $\leq 1$ month was $15.8 \%$. The proportion of children who continued breastfeeding after 6 months was $61.8 \%$. 
Table 1 Demographic characteristics of the participants

\begin{tabular}{|c|c|}
\hline Variables & n (\%) \\
\hline \multicolumn{2}{|l|}{ Sex } \\
\hline Male & $893(51.0)$ \\
\hline Female & $859(49.0)$ \\
\hline \multicolumn{2}{|l|}{ Gestational age (days) } \\
\hline$<259$ (preterm) & $52(3.0)$ \\
\hline$\geq 259$ (term) & $1638(93.5)$ \\
\hline Unknown & $62(3.5)$ \\
\hline \multicolumn{2}{|l|}{ Birth weight (g) } \\
\hline$<2500$ & $49(2.8)$ \\
\hline$\geq 2500$ & $1647(94.0)$ \\
\hline Unknown & $56(3.2)$ \\
\hline \multicolumn{2}{|l|}{ Household income } \\
\hline$\leq 2000$ & $432(24.7)$ \\
\hline$>2000$ and $\leq 3000$ & $532(30.4)$ \\
\hline$>3000$ and $\leq 4000$ & $315(18.0)$ \\
\hline$>4000$ and $\leq 5000$ & $193(11.0)$ \\
\hline$>5000$ & $111(6.3)$ \\
\hline Unknown & $169(9.6)$ \\
\hline \multicolumn{2}{|c|}{ Paternal educational level (years) } \\
\hline$\leq 12$ & $520(29.7)$ \\
\hline$>12$ and $<16$ & $486(27.7)$ \\
\hline$\geq 16$ & $680(38.8)$ \\
\hline Unknown & $66(3.8)$ \\
\hline \multicolumn{2}{|c|}{ Maternal educational level (years) } \\
\hline$\leq 12$ & $454(25.9)$ \\
\hline$>12$ and $<16$ & $362(20.7)$ \\
\hline$\geq 16$ & $809(46.2)$ \\
\hline Unknown & $127(7.2)$ \\
\hline \multicolumn{2}{|c|}{ Age at each assessment (months; mean; SD) } \\
\hline $\mathrm{T} 1$ & $5.5(1.2)$ \\
\hline $\mathrm{T} 2$ & $14.1(1.0)$ \\
\hline T3 & $26.2(1.3)$ \\
\hline T4 & $38.7(1.4)$ \\
\hline T9 & $99.2(1.4)$ \\
\hline
\end{tabular}

Odds ratios for delays in development based on the duration of breastfeeding

The odds ratio for delayed development at T1 (5.5 months) to T3 (26.2 months) are presented in Table 3. In the six group comparison, odds ratios for delayed development assessed with K-ASQ at T2 (14.1 months) were significantly higher in children breastfed for 1-3 months by 2.21 (95\% CI 1.08, 4.50; crude) or 2.63 (95\% CI 1.20, 5.77; adjusted) folds, compared to the reference group (children breastfed for 3-6 months). The comparison of two groups at T3 (26.2 months) presented
Table 2 Proportion of the participants in each breastfeeding duration category

\begin{tabular}{lll}
\hline & $\mathbf{n}$ & \% \\
\hline Never breastfed & 45 & 2.6 \\
$\leq 1$ month & 231 & 13.2 \\
$>1$ month to $\leq 3$ month & 281 & 16.0 \\
$>3$ months to $\leq 6$ months & 205 & 11.7 \\
$>6$ months to $\leq 12$ months & 445 & 25.4 \\
$>12$ months or $\leq 18$ months & 381 & 21.7 \\
$>18$ months & 164 & 9.4 \\
Total & 1752 & 100.0 \\
\hline
\end{tabular}

significantly higher odds ratios for delayed development by 1.45 -fold ( $95 \%$ CI 1.02, 2.07; crude) in children breastfed for $\leq 3$ months than those breastfed for $>3$ months. In some development assessments (i.e., Denver II at T1 and T3), children breastfed for $\leq 1$ month presented lower odds ratios for development delay. However, these odds ratios did not reach significance. The odds ratio for language development delay at T4 showed no significant differences among the six groups. Although children breastfed for $\leq 3$ months showed significantly higher odds ratio for delay in expressive language by 1.64 folds (95\% CI 1.17, 2.30; crude), its significance was lost after adjustment. In the performance of intelligence at T9, children breastfed for > 18 months revealed a higher odds ratio $(2.54 ; 95 \%$ CI 1.09 , 5.90; crude model) for delayed development compared with children breastfed for 3-6 months.

\section{Comparison of cognitive function scores based on the duration of breastfeeding}

The comparison of scores for each cognitive function test as a continuous variable are presented in Table 4 and Table S2. The subscales of communication $(F=3.72 ; p=$ 0.002; only in crude model) and problem-solving $(F=3.09$; $p=0.009)$ at T2 (14.1 months) differed significantly among the six groups of breastfeeding duration, with a higher performance in children breastfed $>3$ months than children breastfed for $\leq 3$ months. The scores on K-ASQ at T1 and T3 among the six groups did not differ significantly.

Language development at T4 (38.7 months) assessed with REVT presented significant differences among the six groups on the expressive language subscale $(F=3.74$; $p=0.002$ ), with a higher performance in children breastfed for $>3$ months than children breastfed for $\leq 3$ months. However, scores on the receptive language subscale did not differ significantly among the groups.

The performance at T9 assessed by M-FIT showed no significant differences among the six groups. Despite significant differences in the calculation subscale $(\mathrm{F}=2.43 ; p=$ $0.033)$, the significance was lost after adjusting for covariates and multiple comparisons. 


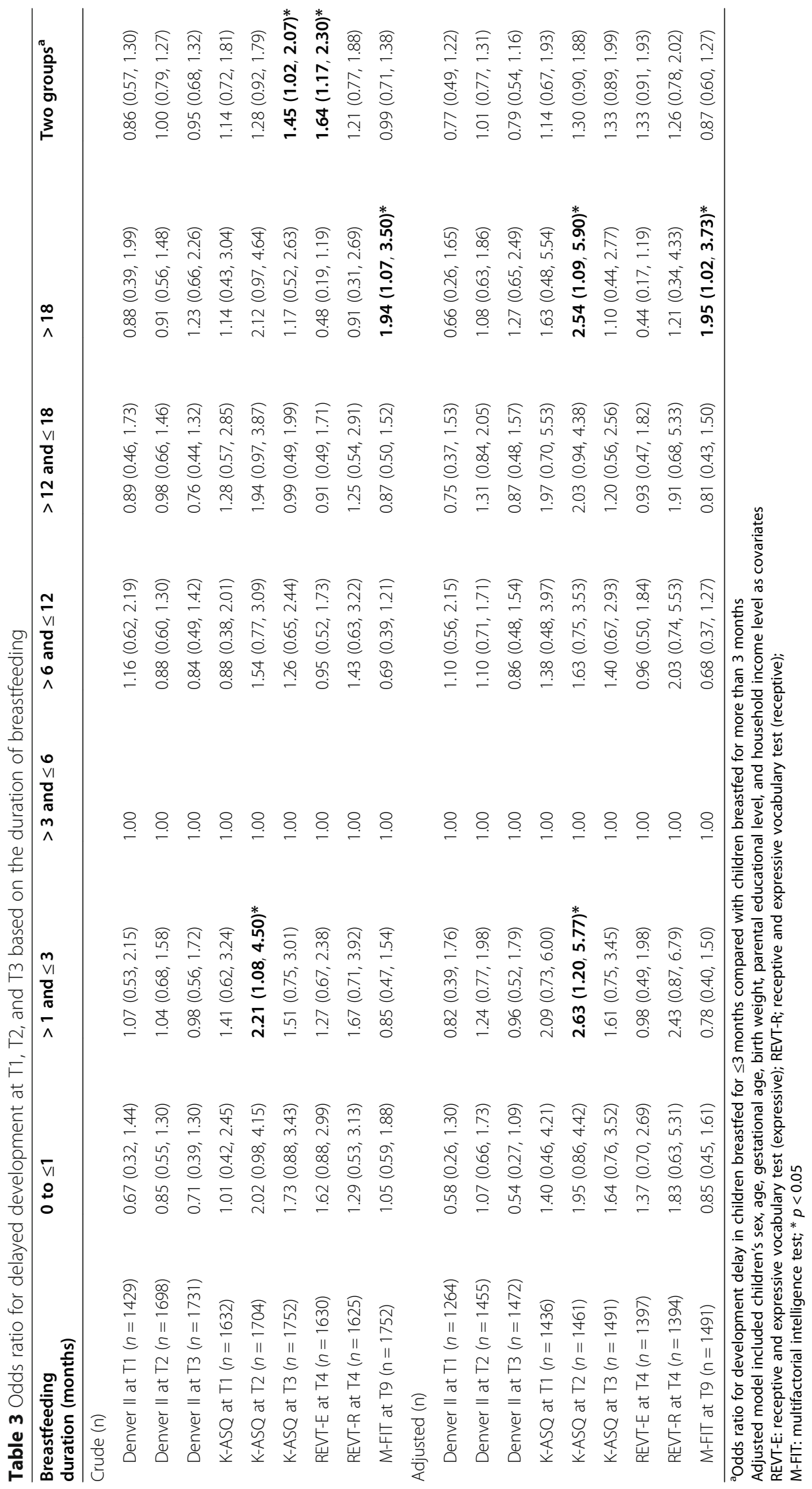




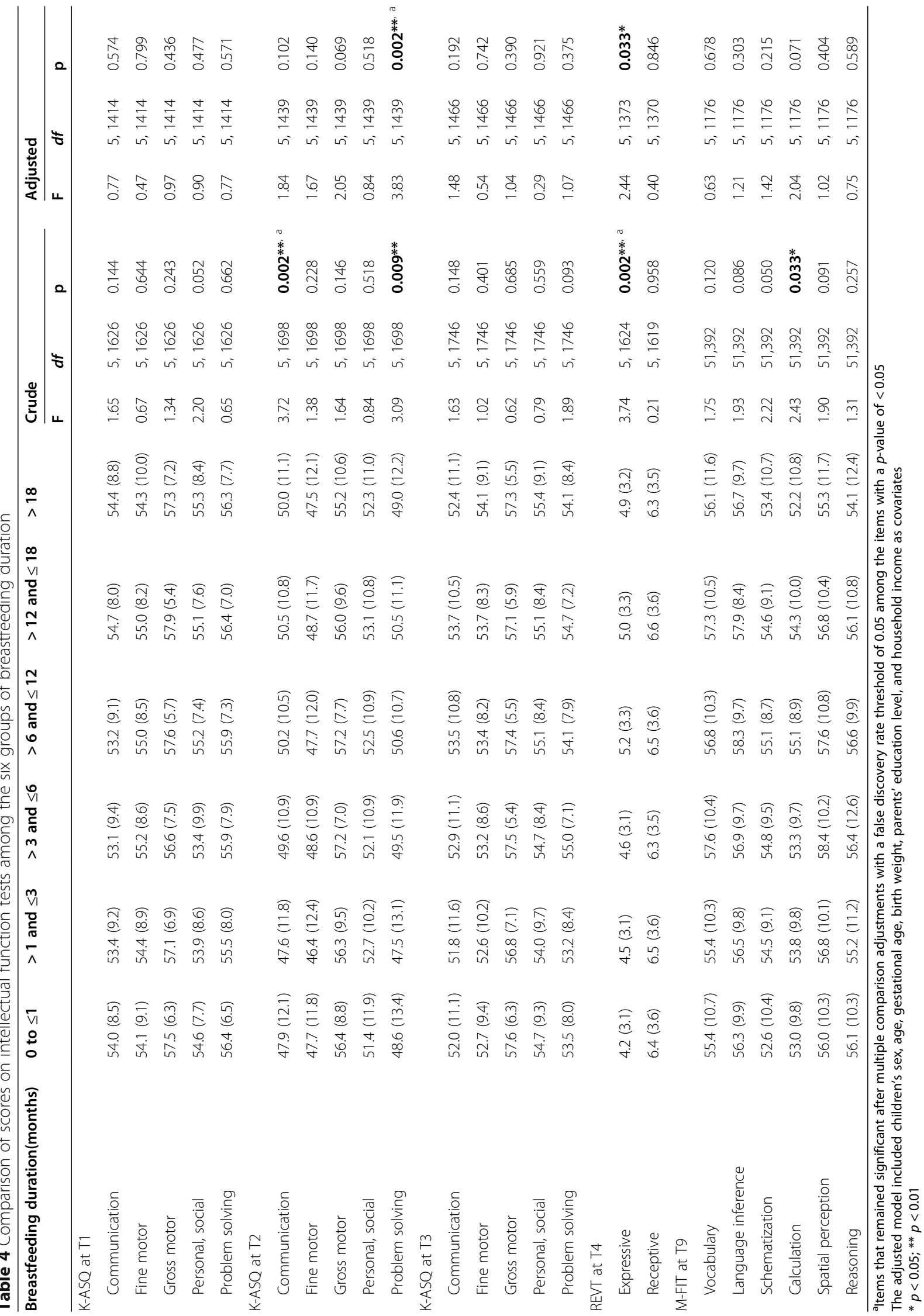




\section{Discussion}

\section{Prevalence of breastfeeding}

The present study investigated the association between breastfeeding and cognitive function in children from 5.5 months to 8 years of age using multiple assessment tools and a prospective design. The prevalence of breastfeeding in our study is comparable to previous studies. Despite evidence of the beneficial effects of breastfeeding on the health of mother and child, the prevalence of breastfeeding was substantially different between countries, with a clear tendency of lower breastfeeding duration and prevalence in wealthier countries [1]. For instance, the proportion of children who were everbreastfed in our study was $97.4 \%$. The previously reported proportion of ever-breastfed children in most countries was over $90 \%$ and was especially high in lowincome countries. However, some high-income countries such as France (63\%), Spain (77\%), Ireland (55\%), and the United States (79\%) had substantially lower proportions of ever-breastfed children [1]. The proportion of children who continued breastfeeding after 6 months was $61.8 \%$ in our study. The average proportion of children who continued breastfeeding after 6 months was lower than $50 \%$ in high-income countries, with especially low proportions in Denmark (13\%), France (23\%), Canada (30\%), and the United Kingdom (34\%) [1]. The previously reported proportion of breastfeeding at 6 months in Korea was $61 \%$, which is consistent with the present findings [21]. The prevalence of breastfeeding in Korea is reported to have increased remarkably since the lowest prevalence in 2000, which is encouraging news for the health of children [21]. Moreover, the infant mortality rate decreased markedly from 9.9 children per 1000 live births in 1993 to 3.2 in 2009, despite the lack of direct association between increased prevalence of breastfeeding and decreased infant mortality rate [22].

\section{Early development}

Early development of infants at T1 (5.5 months), T2 (14.1 months), and T3 (26.2 months) assessed by Denver II showed no significant differences in odds ratios for developmental delay between the groups of breastfeeding duration. These are inconsistent findings with previous studies. Barros et al. reported significantly higher suspected developmental delay at the age of 1 -year assessment in children breastfed for < 1 month (42.4\%) compared to those breastfed for $\geq 9$ months (25.5\%) [23]. Wang and Wu [24] also reported significantly higher developmental delay in the persona-social domain of Denver II assessed at 1 year of age in non-exclusively breastfed children (36\%) compared to exclusively breastfed children (21\%).

The results of the early development assessment with K-ASQ presented different aspects than Denver II assessment. The odds ratios to have atypical scores in at least one subdomain of K-ASQ at T2 (14.1 months) was significantly higher by 2.63 -fold in children breastfed for 1-3 months than the reference group (children breastfed for 3-6 months). However, there were no significant differences in odds ratios for developmental delay assessed with K-ASQ at T1 (5.5 months) and T3 (26.2 months).

In the comparison of the K-ASQ score as a continuous variable among breastfeeding groups, scores on communication and problem-solving subdomains at T2 (14.1 months) and T3 (26.2 months) in children breastfed for $>3$ months were significantly higher than the children breastfed for $\leq 3$ months. These are consistent with the findings of previous studies on early development using the ASQ, which have reported the benefits of breastfeeding on early development. An Irish study of 11,134 children that assessed early development with the ASQ at 9 months old reported the positive effect of breastfeeding on gross motor, fine motor, problem-solving and personal-social skills [25]. A French study with 1999 3year-old children also reported that ever-breastfed children scored 6.2 points higher on the ASQ than neverbreastfed children [26]. The study also reported a significant positive association between exclusively breastfed infants and higher scores on the problem-solving domain of the ASQ. An Australian cohort study with 2868 children reported that infants breastfed for $\geq 4$ months had higher scores in fine motor skills and communication assessed at ages of 1 and 3 years. Infants who were breastfed for $<4$ months were also more likely to have at least one atypical score across the subdomains compared to children breastfed for $\geq 4$ months [27].

\section{Cognitive function in middle childhood and at school age} There were significant differences in cognitive function assessed using the vocabulary test (REVT) among the groups of breastfeeding duration. There was no difference in receptive language score among the six groups of breastfeeding duration. However, when grouped by children who were breastfed for $>3$ months or $\leq 3$ months, those breastfed for $>3$ months scored significantly higher on the vocabulary test. This is consistent with previous findings for language development in middle childhood based on breastfeeding duration. An Australian cohort study with 1195 children assessed language ability with the Peabody Picture Vocabulary Test $($ mean $=100 ; \mathrm{SD}=15)$ and reported that children who were breastfed for $>6$ months presented higher mean scores ( 3.56 points at 5 years and 4.04 points at 10 years, respectively) than children who were neverbreastfed [28].

Results for the association between breastfeeding and cognitive function during school days were not significant. There was a significant difference in the scores on 
the M-FIT subscale of calculation in the comparison of six groups and scores on the vocabulary and language inference in the comparison of two groups (children breastfed for $>3$ months versus $\leq 3$ months), with a favorable outcome due to longer breastfeeding duration on the cognitive development. However, the significance was lost after adjusting for confounding variables. These findings are comparable with previous studies which reported the positive associations between the cognitive function of school-age children and breastfeeding duration [29-31]. For instance, children born preterm who were breastfed had higher IQ scores by 7.6 points (about half a standard deviation) at 8 years than never-breastfed children [24]. An Irish study with 8226 9-year-old school children also reported that ever-breastfed children scored significantly higher percentage points on reading and mathematics than never-breastfed children [31]. Huang et al. also reported that breastfeeding had a significant association with higher intelligence and that the association remained significant during the schooling and adolescent period [32].

\section{Limitations}

The present study has some limitations to note. First, due to the characteristics of longitudinal cohort studies, a substantial number of subjects did not participate in the follow-up assessments. Notably, some participants were excluded from the adjusted model analysis due to missing covariate data. The missing data may bias the relationship between breastfeeding and children's cognitive function. Thus, future study of a more complete dataset with covariate analysis is warranted. Second, although we tried to include important sociodemographic covariates, all covariates could not be included. For instance, previous studies indicated that maternal IQ is a major moderating factor for the association between breastfeeding and children's intelligence, which was not included in our study $[6,33]$. In addition, previous studies included two extents of breastfeeding in their analysis: "any" or "exclusive." However, we did not collect such information on the extent of breastfeeding. Thus, future studies are warranted to include more detailed information on the related demographic variables and extent of breastfeeding to confirm our findings. Third, our study included many multiple comparisons due to various outcome assessments. Moreover, some significant findings were insignificant after multiple comparison adjustments. Despite these insignificant levels, associations contradictory to our main findings between the prevalence of breastfeeding and delayed development were observed in some development assessments (e.g., lower odds ratio in children breastfed for a lesser period with development delay in Denver II assessment at T1 and T3). The significance level may be influenced by sample number or size of the differences in outcome variables. Thus, although the sample size of our study is not small, a future study with a larger sample size would provide further information to confirm our findings. Despite these limitations, the present study has the strength of using multiple tools at multiple time points to assess children's cognitive development using a prospective design.

\section{Conclusion}

The findings of our study present a generally positive association between breastfeeding and cognitive function from early childhood through to school age. In contrast, development assessed with some tools (i.e., Denver II) and at some points (T1-5.5 months) revealed null findings for the association. Many previous studies support the finding that there are positive associations between breastfeeding and cognitive development. However, the mean difference (effect size) in cognitive development due to breastfeeding was only 3.44 points (about onethird of a standard deviation), which is reduced again by the adjustment for maternal IQ [6]. Considering these findings comprehensively, breastfeeding is not considered a critical factor in the cognitive development of children. Other studies have also reported that the observed advantage of breastfeeding on IQ score is actually due to genetic and socioenvironmental factors. When the results are adjusted for covariates such as maternal IQ, the effect of breastfeeding on cognitive function was insignificant [34, 35]. Thus, breastfeeding should not be interpreted to have medical benefits for cognitive development. Another study on 12-year-old twins stratified by maternal education level reported a significant effect of breastfeeding on cognition in all strata of maternal education level, although much of the individual difference in cognition scores was accounted for by genetic factors $(80 \%)$ [33]. Although the reported effects are not significant, it is worthwhile to continue breastfeeding for the possible beneficial effect on children's cognitive development. In addition, more research to investigate the underlying mechanism for the association between breastfeeding and cognitive development is warranted.

\section{Supplementary information}

Supplementary information accompanies this paper at https://doi.org/10. 1186/s13006-020-00326-4.

Additional file 1: Supplement Table S1. Regional distribution of the participants. Supplement Table S2. Comparison of scores on intellectual function tests between children grouped based on breastfeeding duration.

\section{Abbreviations}

ANCOVA: Analysis of variance and analysis of covariance; ASQ: Ages and Stages Questionnaire; K-ASQ: Korean Ages and Stages Questionnaire; M- 
FIT: Multifactorial intelligence test; PSKC: Panel Study on Korean Children; REVT: Receptive and Expressive Vocabulary Test

\section{Acknowledgments}

The authors wish to thank the Korea Institute of Child Care and Education, which provided the raw data.

\section{Authors' contributions}

Conception and design of the study: KM Kim and JW Choi. Acquisition and analysis of data: KM Kim. Original draft and tables: KM Kim. Final editing of manuscript: JW Choi. The author(s) read and approved the final manuscript.

\section{Funding}

This research did not receive any specific grant from funding agencies in the public, commercial, or not-for-profit sectors.

\section{Availability of data and materials}

The datasets used and/or analyzed during the current study are available from the corresponding author on reasonable request.

\section{Ethics approval and consent to participate}

We provided parents with information on the purpose and procedure of the study and collected written informed consent from them before enrollment. This study was performed in accordance with the ethical standards laid down in the 1964 Declaration of Helsinki and its later amendments. The study protocol was approved by the Institutional Review Board of the Korean Institute of Child Care of Education (KICCEIRB-2016-07).

\section{Consent for publication}

Not applicable.

\section{Competing interests}

The authors declare that they have no competing interests.

\section{Author details}

${ }^{1}$ Department of Psychiatry, Dankook University Hospital, Cheonan, Republic of Korea. ${ }^{2}$ Department of Psychiatry, Dankook University College of Medicine, 119 Dandae-ro, Dongnam-gu, Cheonan, Chungnam-do 31116, Republic of Korea. ${ }^{3}$ Department of Psychiatry, Gyeongsang National University Hospital, 79, Gangnam-ro, Jinju-si, Gyeongsangnam-do 52727, Republic of Korea.

Received: 6 March 2020 Accepted: 24 September 2020

Published online: 29 September 2020

\section{References}

1. Victora CG, Bahl R, Barros AJ, et al. Breastfeeding in the 21st century: epidemiology, mechanisms, and lifelong effect. Lancet. 2016;387:475-90.

2. Victoria C. Effect of breastfeeding on infant and child mortality due to infectious diseases in less developed countries: a pooled analysis. Lancet (British edition). 2000;355:451-5.

3. Horta BL, Victora CG. Short-term effects of breastfeeding: a systematic review on the benefits of breastfeeding on diarrhoea and pneumonia mortality. Geneva: World Health Organization; 2013.

4. Hoefer C, Hardy MC. Later development of breast fed and artifically fed infants: comparison of physical and mental growth. J Am Med Assoc. 1929; 92:615-9.

5. Anderson JW, Johnstone BM, Remley DT. Breast-feeding and cognitive development: a meta-analysis. Am J Clin Nutr. 1999;70:525-35.

6. Horta BL. Loret de Mola C, Victora CG. Breastfeeding and intelligence: a systematic review and meta-analysis. Acta Paediatr. 2015;104:14-9.

7. Kramer MS, Aboud F, Mironova E, Vanilovich I, Platt RW, Matush L, et al. Breastfeeding and child cognitive development: new evidence from a large randomized trial. Arch Gen Psychiatry. 2008;65:578-84.

8. Brion MJ, Lawlor DA, Matijasevich A, Horta B, Anselmi L, Araújo CL, et al. What are the causal effects of breastfeeding on IQ, obesity and blood pressure? Evidence from comparing high-income with middle-income cohorts. Int J Epidemiol. 2011;40:670-80

9. Victora CG, Horta BL, Loret de Mola C, Quevedo L, Pinheiro RT, Gigante DP, et al. Association between breastfeeding and intelligence, educational attainment, and income at 30 years of age: a prospective birth cohort study from Brazil. Lancet Glob Health. 2015;3:e199-205.
10. Park S, Kim BN, Kim JW, Shin MS, Yoo HJ, Cho SC. Protective effect of breastfeeding with regard to children's behavioral and cognitive problems. Nutr J. 2014;13:111.

11. Kim Jl, Kim BN, Kim JW, Hong SB, Shin MS, Yoo HJ, et al. Breastfeeding is associated with enhanced learning abilities in school-aged children. Child Adolesc Psychiatry Ment Health. 2017;11:36.

12. Squires J, Bricker D, Potter L. Revision of a parent-completed developmental screening tool: ages and stages questionnaires. J Pediatr Psychol. 1997;22:313-28.

13. Heo KH, Squires J, Lee SY, Lee JS. KASQ: Korean ages and stages questionnaires/parent-completed development screening tool. Seoul: Seoul community rehabilitation center; 2006.

14. Frankenburg WK, Dodds J, Archer P, Shapiro H, Bresnick B. The Denver II: a major revision and restandardization of the Denver developmental screening test. Pediatrics. 1992;89:91-7.

15. Shin H, Kwon B, Lim S. Validity of Korean version of Denver II in screening children with developmental risk. Korean J Child Health Nurs. 2005;11:316-21.

16. Panel Study on Korean Children. https://panel.kicce.re.kr/panel/index.do (2020). Accessed 1 Aug 2020

17. Kim YT, Hong GH, Kim KH. Content and reliability analyses of the receptive and expressive vocabulary test (REVT). Commun Sci Disord. 2009;14:34-45.

18. Mortensen EL, Michaelsen KF, Sanders SA, Reinisch JM. The association between duration of breastfeeding and adult intelligence. JAMA. 2002;287:2365-71.

19. Benjamini $Y$, Hochberg $Y$. Controlling the false discovery rate: a practical and powerful approach to multiple testing. J R Stat Soc B (Methodological). 1995;57(1):289-300.

20. Household income in 2008. Daejeon: Statistics Korea; 2018. http://kosis.kr/ statHtml/statHtml.do?orgld=101\&tblld=DT_1L9H008\&conn_path=13. Accessed 1 Aug 2020.

21. Chung SH, Kim HR, Choi YS, Bae CW. Trends of breastfeeding rate in Korea (1994-2012): comparison with OECD and other countries. J Korean Med Sci. 2013;28:1573-80.

22. Chang J-Y, Lee KS, Hahn W-H, Chung S-H, Choi Y-S, et al. Decreasing trends of neonatal and infant mortality rates in Korea: compared with Japan, USA, and OECD nations. J Korean Med Sci. 2011;26:1115-23.

23. Barros FC, Victora CG, Morris SS, Halpern R, Horta BL, Tomasi E. Breast feeding, pacifier use and infant development at 12 months of age: a birth cohort study in Brazil. Paediatr Perinat Epidemiol. 1997;11:441-50.

24. Wang YS, Wu SY. The effect of exclusive breastfeeding on development and incidence of infection in infants. J Hum Lact. 1996:12:27-30.

25. McCrory C, Murray A. The effect of breastfeeding on neuro-development in infancy. Matern Child Health J. 2013;17:1680-8.

26. Bernard JY, De Agostini M, Forhan A, Alfaiate T, Bonet M, Champion V, et al. Breastfeeding duration and cognitive development at 2 and 3 years of age in the EDEN mother-child cohort. J Pediatr. 2013;163:36-42.

27. Oddy WH, Robinson M, Kendall GE, Li J, Zubrick SR, Stanley FJ. Breastfeeding and early child development: a prospective cohort study. Acta Paediatr. 2011;100:992-9.

28. Whitehouse AJ, Robinson M, Li J, Oddy WH. Duration of breast feeding and language ability in middle childhood. Paediatr Perinat Epidemiol. 2011;25:44-52.

29. Lucas A, Morley R, Cole TJ, Lister G, Leeson-Payne C. Breast milk and subsequent intelligence quotient in children born preterm. Lancet. 1992;339:261-4.

30. Smithers LG, Golley RK, Mittinty MN, Brazionis L, Northstone K, Emmett P, et al. Dietary patterns at 6, 15 and 24 months of age are associated with IQ at 8 years of age. Eur J Epidemiol. 2012;27:525-35.

31. McCrory C, Layte R. The effect of breastfeeding on children's educational test scores at nine years of age: results of an Irish cohort study. Soc Sci Med. 2011;72:1515-21.

32. Huang J, Peters KE, Vaughn MG, Witko C. Breastfeeding and trajectories of children's cognitive development. Dev Sci. 2014:17:452-61.

33. Bartels M, Van Beijsterveldt CE, Boomsma DI. Breastfeeding, maternal education and cognitive function: a prospective study in twins. Behav Genet. 2009;39:616.

34. Der G, Batty GD, Deary IJ. Effect of breast feeding on intelligence in children: prospective study, sibling pairs analysis, and meta-analysis. BMJ. 2006:333:945.

35. Jacobson SW, Chiodo LM, Jacobson JL. Breastfeeding effects on intelligence quotient in 4-and 11-year-old children. Pediatrics. 1999;103:e71.

\section{Publisher's Note}

Springer Nature remains neutral with regard to jurisdictional claims in published maps and institutional affiliations. 